\title{
El patrimonio digital en el Perú
}

\author{
Fernando Martín Robles Sotomayor*
}

- Abogado y Licenciado en Educación por la Pontificia Universidad Católica del Perú, Magister en Educación Superior por la Universidad Nacional de San Agustin, Docente Asociado de la Academia de la Magistratura, Doctorando en Derecho por la Universidad Federico Villarreal.

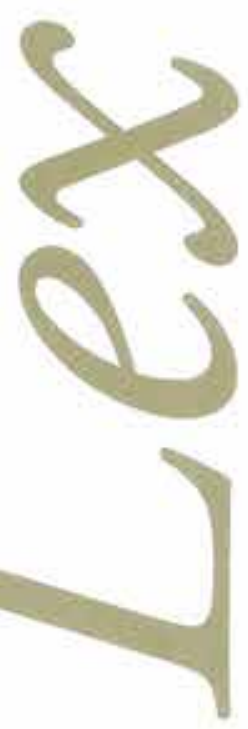



n 1972 se comenzó a proteger en el Perú el Patrimonio Documental, asignándose dicha función al Archivo General de la Nación. En la última década, la Unesco formuló la Carta para la Preservación del Patrimonio Digital, impulsando, de esa manera, a que las distintas naciones adquieran conciencia, a partir del crecimiento explosivo de la informática y la masificación del uso del internet, de la producción de gran cantidad de documentación digital que, sin embargo, se está perdiendo por la facilidad de ser modificada, la rápida obsolescencia de sus soportes y la ausencia de normatividad legal e interés técnico en su preservación.

Sin embargo, el Patrimonio Digital merece ser protegido en cuanto tiene un valor cultural análogo al del Patrimonio Documental. Los archivos históricos, en cuyo ámbito de conservación debe ser incluido el Patrimonio Digital, mediante el Decreto Supremo No 0032010-ED del 15 de Enero de 2010, dejaron de ser responsabilidad del Archivo General de la Nación, creándose como un órgano de línea del Instituto Nacional de Cultura a la Dirección Nacional de Archivo Histórico que, en adelante, es el responsable del archivo y preservación del Patrimonio Digital con valor histórico. Sin embargo, han transcurrido seis meses de la dación de esa norma y no se ha apreciado ningún avance al respecto. Con la posible creación del Ministerio de Cultura, es de esperar que el Estado peruano comience a enfrentar con mayor responsabilidad la tarea de preservar el Patrimonio Digital para las generaciones del futuro como un legado de nuestro mundo presente.

Con 84 de 103 zonas de vida identificadas en el mundo, gran belleza paisajística y una riqueza arqueológica impresionante constituida por construcciones precolombinas que han subsistido al paso del tiempo, el Perú es un país privilegiado. Además de ello, cuenta con una pluriculturalidad que se encuentra patentizada en nuestras diversas comunidades campesinas y nativas. En suma, tenemos un patrimonio histórico y cultural que pocos países poseen, por esta razón nuestro patrimonio es "nuestra herencia del pasado, nuestros bienes actuales y lo que legamos a las generaciones futuras"

1 Unesco. "Directrices para la Preservación del Patrimonio Digital". p. 22. http://unesdoc.unesco.org images/ 0013/001300/130071s.pdf, 22 Julio, 2010. 
En la época de la "sociedad de la información", en la que nuestra vida sin computadoras e internet es casi impensable, en la que para cualquier profesional, más aún el abogado, es obligatorio conocer de informática, ¿qué patrimonio está surgiendo?

Cotidianamente, elaboramos documentos en Microsoft Word u otros procesadores de texto, diseñamos presentaciones en Power Point, subimos fotos o comentarios a nuestro Facebook, Twitter o Hi5, remitimos correos electrónicos, publicamos un breve artículo en un blog, añadimos una definición en Wikipedia, realizamos una compra por Internet, celebramos un contrato electrónico, subimos una foto en Flickr o un video en Youtube. ¿Qué es lo que estamos creando cotidianamente? Objetos digitales diversos que, en la medida de su valor, se convertirán para el hombre de hoy y el de mañana en patrimonio, pero Patrimonio Digital.

"Se podría definir el Patrimonio Digital como el conjunto de objetos, creados de forma numérica $o$ procedentes de la digitalización de documentos analógicos, que tienen un valor perdurable para una comunidad. Estos materiales precisan de un sistema informático para ser producidos y consultados y están compuestos por información textual, icónica, sonora, programas de ordenador o por una combinación de todas o algunas de estas categorías, en cuyo caso recibe la denominación de multimedia, codificada en formato digital". ${ }^{2}$ Cuando hablamos del Patrimonio Digital, ¿¿de qué hablamos? Por otro lado, ¿̇es Patrimonio Digital todo lo que hacemos en la computadora? Realmente, no. Por eso, la Unesco aclara que "no todos los objetos digitales merecen ser conservados. El patrimonio digital está constituido únicamente por aquellos que se considera que poseen un valor permanente". 3

\section{Carta para la Preservación del Patrimonio Digital de la Unesco}

En París, en abril del año 2003, durante la segunda reunión del Consejo Intergubernamental del "Programa Información para Todos" celebrada en la sede de la Organización de las Naciones Unidas para la Educación, la Ciencia y la Cultura (Unesco), se presentó la versión revisada de la Carta para la Preservación del Patrimonio Digital, luego de un periodo de consultas a los países miembros. Resulta interesante citar los alcances de aquello que la Carta denomina "Patrimonio Digital": "El patrimonio digital consiste en recursos únicos que son fruto del saber o la expresión de los seres humanos. Comprende recursos de carácter cultural, educativo, científico o administrativo e información técnica, jurídica, médica y de otras clases, que se generan directamente en formato digital o se convierten a éste a partir de material analógico ya existente. Los productos

2 García Melero, Luis Angel. "La recopilación y conservación del patrimonio digital". p 7. http://bv.gva.es/documentos/ Ponencias/Melero.pdf, 22 Julio, 2010.

3 Unesco. op cit. 
"de origen digital" no existen en otro formato que el electrónico". ${ }^{4}$ La carta aborda en forma genérica, pero firme, aspectos de ineludible tratamiento relativos al acceso a este patrimonio, al peligro de su pérdida, a la necesidad de actuar y de brindar medidas que incidan en todo el ciclo de vida de la información digital, a elaborar estrategias y políticas para seleccionar los elementos que deben conservarse, a las modalidades de protección de este legado brindando. Inclusive, considera algunos alcances de lo que deben contemplar los Estados Miembros en cuanto a funciones y atribuciones que involucren a todos los sectores de la sociedad, estableciendo alianzas y cooperación efectiva a nivel internacional para difundir en forma debida los alcances de ésta temática con visión de futuro.

La carta también alude a que los Estados miembro habrán de disponer de mecanismos jurídicos e institucionales adecuados para garantizar la protección del patrimonio digital, haciendo que la legislación sobre archivos se aplique al patrimonio digital como parte de una política nacional de preservación. Como medida específica relativa al tratamiento de la integridad del documento digital, se propone prevenir la manipulación o modificación deliberada de éste por lo que estima de suma importancia disponer de un marco, tanto jurídico como técnico, en el que se proteja la autenticidad.

Con el uso de la tecnología para la producción de documentos, surgen problemas como la vulnerabilidad de la intimidad de las personas, su rápida obsolescencia o la pérdida de datos por las migraciones. Se considera que los soportes informáticos tienen un valor de eficiencia jurídica y que se debe fomentar la seguridad y la confianza en la comunicación electrónica. Además, es necesario tener presente las condiciones ambientales para la conservación de los diferentes soportes informáticos.

Diversos países en el mundo ya vienen desarrollando importantes iniciativas para la conservación del patrimonio digital. Estos proyectos normalmente están dirigidos por universidades, bibliotecas o instituciones gubernamentales en el ámbito de la cultura que, preocupadas por la preservación del patrimonio digital, realizan trabajos para su adecuado almacenamiento y archivo. En América, es posible que el principal sea el proyecto canadiense denominado Interpares', proyecto de investigación internacional para la preservación permanente de archivos electrónicos auténticos que abarca un horizonte temporal de doce años, de 1999 a 2012.

Unesco. "Carta para la Preservación del Patrimonio Digital". http://arpa.ucv.cl/texto/Preservaci\%F3nPatrimonioDigit alUNESCO.pdf, 22 Julio, 2010.

5 International Research on Permanent Authentic Records in Electronic Systems. http://www.interpares.org 22 Julio, 2010. 


\section{El Patrimonio Documental de la Nación}

El punto de partida en nuestro país, para pensar en la protección del patrimonio digital, lo encontramos en el año 1972, cuando se promulgó la Ley de Defensa, Conservación e Incremento del Patrimonio Documental de la Nación. ${ }^{6}$ Mediante esta ley, se reconoció la importancia de los documentos como fuente para el conocimiento y se declaró de utilidad pública la defensa, conservación e incremento de estos obligando al Estado a protegerlos. Por primera vez, desde la creación de la República, se reconocía la importancia de la preservación de los documentos, considerándolos como patrimonio nacional y dictándose una serie de medidas de protección.

El Decreto Ley constituyó una norma verdaderamente innovadora - pese a poseer sólo 17 artículos - debido a que estableció, en primer lugar, cómo se encontraba constituido el Patrimonio Documental de la Nación; y, en segundo lugar, recogió instituciones y principios de la doctrina archivística, de manera que se definió lo que era un archivo, los procesos archivísticos de conservación, la transferencia, el servicio y la eliminación de documentos, entre otras.

"El Patrimonio Documental de la Nación está constituido por la Documentación existente en los archivos de todas las reparticiones y organismos del Sector Público Nacional; en los archivos históricos, notariales, eclesiásticos, parroquiales y de conventos, en los archivos particulares y en general por el material documental, aun de origen privado, que sirven de fuente de información para estudios históricos y de desarrollo cultural, social, económico, jurídico o religioso de la Nación".

Definió "Archivo" como la entidad encargada de la conservación, ordenamiento y clasificación de los fondos documentales, debidamente organizados para prestar un servicio eficiente. Es de esta manera que, hace casi cuatro décadas, en el Perú se comenzó a tratar el patrimonio documental, y ese es nuestro punto de partida para pensar en el patrimonio digital que nos refiere la Unesco.

En el Decreto Ley, se estableció que aquella documentación que tuviese más de 30 años, dentro del ciclo de vida de la documentación que obrase en los archivos del Sector Público, sería transferida al Archivo General de la Nación o a los archivos departamentales, arribándose así a la clasificación de archivos en históricos, de gestión e intermedios. 
En estas circunstancias, se asignó al Archivo General de la Nación la función de velar por el cumplimiento de la norma, otorgándole facultades para autorizar la transferencia de la propiedad de bienes integrantes del patrimonio documental de la Nación y para dictar normas en materia de clasificación, conservación y depuración de los archivos.

En 1975, se dictó el Reglamento ${ }^{8}$ del Decreto Ley estableciéndose procedimientos y requisitos para la transferencia documental, el traslado de documentos del Archivo General de la Nación o de los archivos departamentales, salida lícita e ilícita de documentos del país, la elaboración de un registro del patrimonio documental de la Nación en poder de particulares, así como la conservación y la eliminación documental. Dicho reglamento precisó los requisitos que un documento debía tener para ser considerado como patrimonio documental de la Nación.

Sin embargo, a lo largo de tres décadas, el Archivo General de la Nación no prestó atención al patrimonio digital, surgiendo recién inquietudes al respecto en los últimos cinco años. No obstante ello, fue incapaz en su calidad de responsable de preservar el patrimonio documental, de dictar la normatividad necesaria y recomendada por la citada Carta de la Unesco para regular el archivo del patrimonio digital.

\section{El Patrimonio Digital en la actualidad en el Perú}

Pongamos sobre una balanza el patrimonio documental y el patrimonio digital y encontráremos que ambos tienen el mismo valor en la medida en que se convierten en archivos históricos. Es decir, adquieren un valor para la cultura e investigación en el presente y el futuro.

Hoy en día, la producción de documentos digitales gracias a las facilidades de uso y masificación de la informática, supera notablemente la producción de documentos en soporte papel. No obstante lo inapropiada que es, aún mantenemos una cultura de imprimir el documento digital, básicamente porque no se han emitido las normas y directivas necesarias para la conservación del documento digital. Por ello, estamos aún obligados a tener que conservarlo en formato físico, con el consiguiente gasto que ello implica, no sólo económico sino también en lo que se refiere a la conservación de nuestro ambiente y recursos naturales.

A inicios del presente año, se le quitó la enorme responsabilidad al Archivo General de la Nación en esta materia, pues mediante Decreto Supremo No 003-2010-ED del 15 de Enero de 2010, se fusionó la Dirección Nacional de Archivo Histórico al Instituto Nacional de Cultura, convirtiéndose en un órgano de línea de dicha entidad.

8 Normas Legales. Reglamento del Decreto Ley No 19414, aprobado mediante Decreto Supremo No 022-75-ED. 
Han pasado más de seis meses desde la emisión de esa norma, y el Instituto Nacional de Cultura no ha prestado absoluta atención al Patrimonio Digital, tampoco han hecho algo al respecto la Oficina Nacional de Gobierno Electrónico - ONGEI, seguramente más preocupada en la ejecución de las estrategias para el cumplimiento de la Agenda Digital Peruana, aprobada mediante el Decreto Supremo No 031-2006-PCM', del 20 de Junio de 2006, y ante la presión que le representa la celebración, en el mes de noviembre próximo, en la ciudad de Lima de la Tercera Conferencia Ministerial de América Latina y el Caribe sobre la Sociedad de la Información - eLAC 2010. Esta conferencia permitirá evaluar el avance de los diferentes países en sus estrategias de implementación de la sociedad de la información y plantear las acciones a seguir hacia el año 2015.

Se viene anunciando en el Perú la creación del Ministerio de Cultura. El Congreso de la República ya ha dado los primeros pasos. Sin duda alguna, el Instituto Nacional de Cultura será absorbido por dicho organismo ministerial. La pregunta que nos cabe es si alguien se percatará de la existencia de esa invocación de la Unesco para preservar el Patrimonio Digital. ¿Se emitirán, al fin, las normas y se tomarán las acciones para su adecuado archivo en las entidades públicas y privadas?

Día a día, llevamos a cuestas la World Wide Web, absorbidos por el apasionante mundo que nos representa Internet. Asimismo, experimentamos la facilidad de contar con computadoras personales, laptops, notebooks, y de dispositivos cada vez más pequeños, como el Iphone, que nos permiten seguir produciendo masivamente documentos digitales.

Es por ello que, desde el mundo académico, debemos entender y difundir la importancia de la preservación del patrimonio digital. Por ello, es necesario que las entidades estatales tomen conciencia del tema, asuman las recomendaciones internacionales y comiencen a generar la normatividad necesaria para que los especialistas y técnicos en la materia comiencen a aplicar las herramientas tecnológicas para una adecuada conservación del patrimonio digital en el Perú.

9 Normas Legales. Decreto Supremo No 031-2006-PCM. [En línea]. http://www.ongei.gob.pe/normas/0/NORMA_0_ DECRETO $\% 20$ SUPREMO\%20N%20031-2.pdf, 17 Julio, 2010. 


\section{BIBLIOGRAFÍA}

- Archivo General de la Nación. http://www.agn.gob.pe

- Comisión Multisectorial Permanente para el Desarrollo de la Sociedad de la Información en el Perú - La Agenda Digital Peruana. http://www.codesi.gob.pe

- Garcia Melero, Luis Angel. "La Recopilación y Conservación del Patrimonio Digital", http://bv.gva.es/documentos/Ponencias/Melero.pdf

- Interpares - International research on Permanent Authentic Records in Electronic Systems. http://www.interpares.org

- Normas Legales. http://www.elperuano.com.pe

- Oficina Nacional de Gobierno Electrónico e Informática - ONGEI. http://www.ongei. gob.pe

- Unesco. "Carta para la Preservación del Patrimonio Digital", http://arpa.ucv.cl/texto/Pr eservaci\%F3nPatrimonioDigitalUNESCO.pdf

- Unesco. "Directrices para la Preservación del Patrimonio Digital", http://unesdoc.unesco. org/images/0013/001300/130071s.pdf 


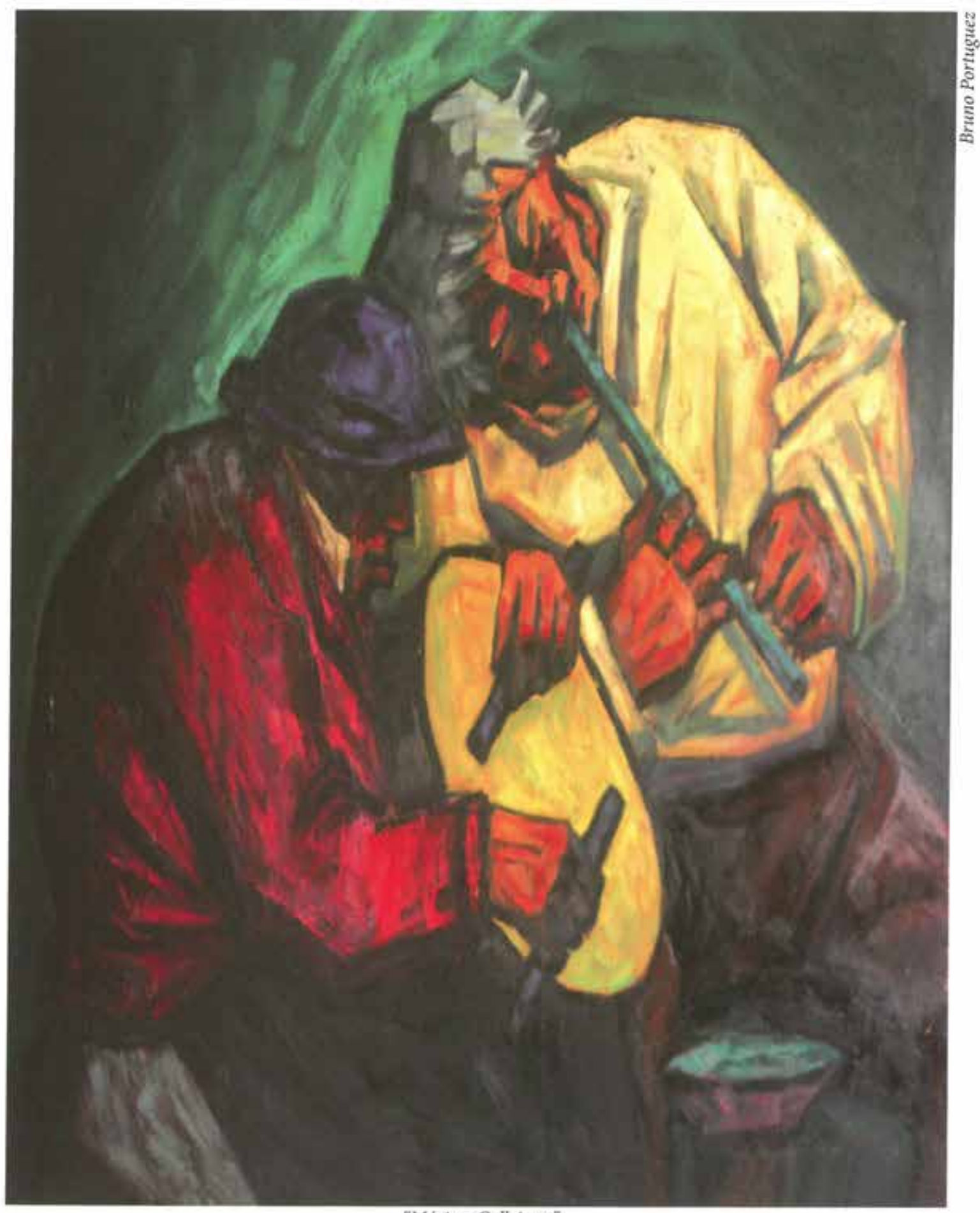

"Músicos Callejeros" 